\title{
$\beta$-Funaltrexamine antagonizes the discriminative stimulus effects of morphine but not naltrexone in pigeons
}

\author{
Charles P. France and James H. Woods \\ Departments of Psychology and Pharmacology, 6322 Medical Science Building, University of Michigan Medical School, \\ Ann Arbor, MI 48109, USA
}

\begin{abstract}
Antagonistic actions of the irreversible, $\mu$-selective antagonist $\beta$-funaltrexamine ( $\beta$-FNA) were evaluated in pigeons trained to discriminate among intramuscular injections of morphine $(5.6 \mathrm{mg} / \mathrm{kg})$, saline, and naltrexone $(10.0 \mathrm{mg} / \mathrm{kg}) . \beta$-FNA administered alone $(1.0$ or $10.0 \mathrm{mg} /$ $\mathrm{kg}$ ) failed to mimic the discriminative stimulus effects of morphine or naltrexone. $\beta$-FNA attenuated the discriminative stimulus effects of morphine. A three-fold larger dose of morphine was required for complete generalization when pigeons were pretreated with a dose of $1.0 \mathrm{mg} / \mathrm{kg} \beta$-FNA. A dose of $10.0 \mathrm{mg} / \mathrm{kg} \beta$-FNA completely antagonized the morphine discriminative stimulus, so that pigeons responded predominantly on the saline key up to doses of morphine that suppressed responding. Doses of $\beta$-FNA that attenuated the effects of morphine had no effect on the discriminative stimulus effects of naltrexone. These results demonstrate that, like naltrexone, $\beta$-FNA attenuates the discriminative stimulus effects of morphine in pigeons and, at sufficiently large doses, antagonizes morphine in an unsurmountable manner. $\beta$-FNA does not, however, share discriminative stimulus properties with naltrexone in these pigeons, and fails to attenuate the discriminative stimulus effects of naltrexone, lending support to the suggestion that naltrexone exerts discriminative stimulus effects under these experimental conditions predominantly by a non-mu opioid mechanism.
\end{abstract}

Key words: Pigeon - Morphine - Naltrexone $-\beta$-Funaltrexamine - Opioid antagonism - Drug discrimination

Discrimination procedures that use two different compounds as training stimuli have been shown to be useful assays for independently or simultaneously characterizing the actions of two or more compounds in the same subjects (White and Holtzman 1981, 1983; France and Woods 1985b). In the present experiment, pigeons trained to discriminate among morphine, saline, and naltrexone were used to study the antagonistic actions of $\beta$-funaltrexamine $(\beta$-FNA). $\beta$-FNA is a purported irreversible, $\mu$-selective opioid antagonist with reversible opioid agonistic actions in rodents (Portoghese et al. 1980; Takemori et al. 1981; Ward et al. 1982). In rhesus monkeys, $\beta$-FNA both attenuates the effects of morphine and, at larger doses, produces

offprint requests to: J.H. Woods muscle relaxation and stupor that are reversed by opioid antagonists (Gmerek and Woods 1985). In pigeons, $\beta$-FNA attenuates the rate-suppressing effects of morphine on fixed-ratio responding for up to $48 \mathrm{~h}$ (France and Woods 1985a), but does not mimic the discriminative stimulus effects of naltrexone or morphine (France and Woods $1985 \mathrm{~b}$ ). There are no previous reports on the capacity of $\beta$-FNA to attenuate the discriminative stimulus effects of opioid agonists or antagonists.

A second objective of this experiment was to describe further the mechanisms of action of morphine and naltrexone as discriminative stimuli in untreated pigeons. We previously reported that small doses of morphine augmented the discriminative stimulus effects of naltrexone in pigeons (France and Woods 1985b), suggesting some opioid contribution to the discriminative stimulus effects of naltrexone in non-dependent pigeons. Because $\beta$-FNA did not substitute for morphine or naltrexone (France and Woods 1985 b), and because of its established opioid antagonistic action (Ward et al. 1982; France and Woods 1985a; Gmerek and Woods 1985), it appeared to be an appropriate compound for testing whether the discriminative stimulus effects of morphine and naltrexone could be antagonized differentially under these conditions. Selective antagonism of morphine or naltrexone would indicate that these compounds acted through different mechanisms as discriminative stimuli in pigeons.

\section{Materials and methods}

Six White Carneaux pigeons (Palmetto, Sumter, SC), previously trained (France and Woods 1985b) to discriminate among morphine, saline, and naltrexone, were maintained at $80 \%$ of their free-feeding weight and housed individually with water and grit available continuously. Experiments were conducted in ventilated, sound-attenuated chambers measuring $36 \times 28 \mathrm{~cm} \times 33 \mathrm{~cm}$ high. On the inside of one wall were mounted three translucent response keys $(2.4 \mathrm{~cm}$ diameter) that could be transilluminated red by $7-\mathrm{W}$ lights located behind each key. Directly below the center response key was a $5 \times 5 \mathrm{~cm}$ square opening through which mixed grain was made available by a food hopper. During reinforcement, a white light illuminated the hopper opening and the key lights were off. Experiments were controlled and data recorded by a Texas Instruments Inc. (Dallas, TX) $960 \mathrm{~A}$ computer located in an adjacent room. The pat- 

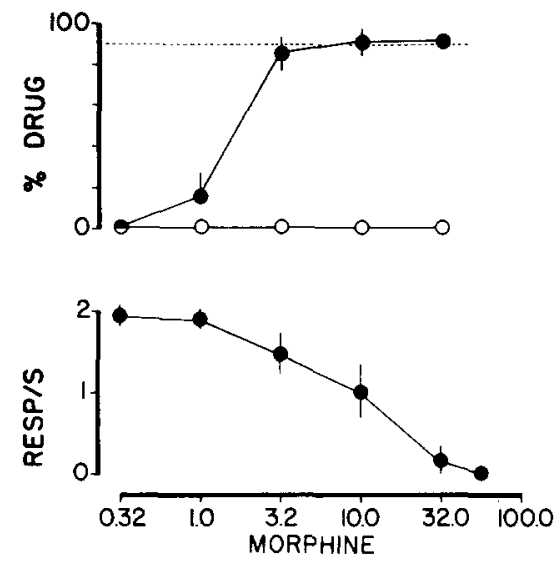

$D O S$

$E$
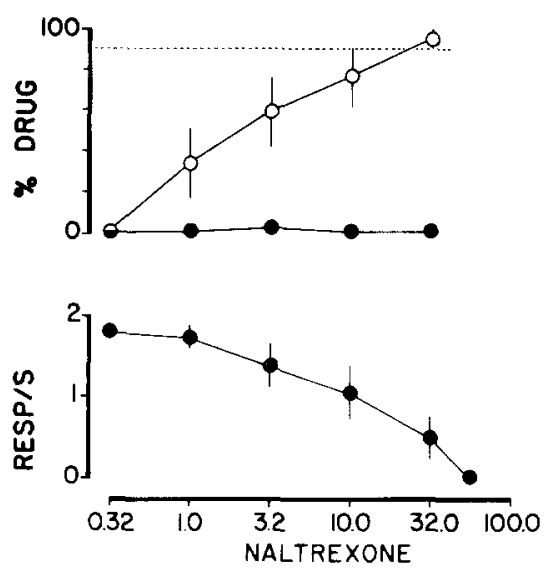

$(M G / K G)$
Fig. 1. Dose effect curves for cumulative doses of morphine (left) and naltrexone (right) in pigeons trained to discriminate among morphine, saline, and naltrexone. Ordinates: upper panels, mean percentage of responses on the morphine (closed symbols) and naltrexone (open symbols) keys \pm 1 SEM, for six pigeons (dashed lines indicate $90 \%$ drug-appropriate responding); lower panels, mean response rate, expressed in responses per $\mathrm{s} \pm 1$ SEM. Abscissa: dose in $\mathrm{mg} / \mathrm{kg}$ body weight
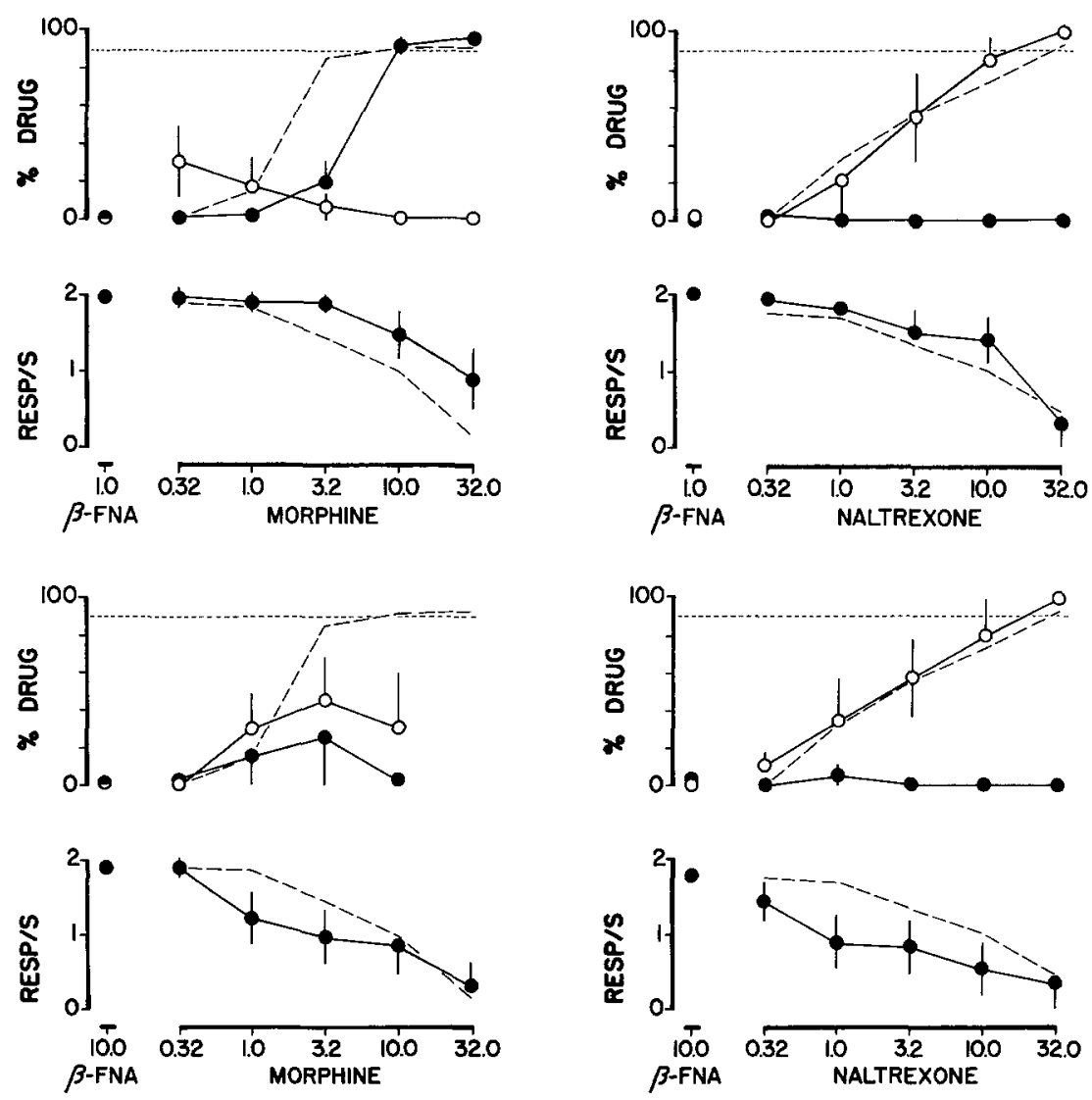

Fig. 2. Dose-effect curves for morphine (left panels) and naltrexone (right panels) following a pretreatment with $1.0 \mathrm{mg} / \mathrm{kg}$ (upper panels) or $10.0 \mathrm{mg} / \mathrm{kg}$ (lower panels) $\beta$-FNA. $\beta$-FNA was administered prior to the first trial (leftmost points) and cumulative doses of morphine or naltrexone were administered prior to subsequent trials. Dashed lines respresent the effects of morphine and naltrexone administered alone, and are the same data as shown in Fig. 1. Other $D \quad O \quad S \quad E \quad(M G / K G)$ designations as in Fig. 1

tern of responding was displayed on cumulative response recorders (Ralph Gerbrands Co., Arlington, MA).

Experiments were conducted 6 or 7 days per week. Training sessions consisted of a single trial which was divided into a 10 -min pretreatment period, during which the chamber was dark and key pecks had no programmed consequence, and a $20-\mathrm{min}$ response period, during which the three keys were illuminated and food could be earned by emitting 20 consecutive responses (FR20) on the injectionappropriate key (for all pigeons: left key, morphine-appropriate; center key, saline-appropriate; right key, naltrexone appropriate). Saline, $5.6 \mathrm{mg} / \mathrm{kg}$ morphine, or $10.0 \mathrm{mg} / \mathrm{kg}$ naltrexone was injected immediately prior to the pretreatment period. Training sessions ended after 40 food presentations or $30 \mathrm{~min}$, whichever occurred first.

Tests were conducted whenever pigeons satisfied the testing criteria which were 3 consecutive days with fewer than 20 responses on either of the injection-inappropriate keys prior to the first reinforcement, and at least $90 \%$ of the total responses on the injection-appropriate key. Test sessions consisted of 5 or 6 discrete, 15-min trials. Each trial was preceded by an injection followed by a 10-min 
pretreatment period and a 5 -min response period, during which a maximum of ten food presentations could be earned by emitting 20 consecutive responses on any of the three keys. A trial ended after ten reinforcements or $15 \mathrm{~min}$, whichever occurred first, and the interinjection interval was always $15 \mathrm{~min}$. Morphine and naltrexone were administered using a cumulative dosing procedure (e.g., Bertalmio et al. 1982) up to doses that suppressed responding. For tests of antagonism, 1.0 or $10.0 \mathrm{mg} / \mathrm{kg} \beta$-FNA was injected prior to the first trial, followed by cumulative doses of morphine or naltrexone on subsequent trials.

Morphine sulfate (Merck Pharmaceuticals, St. Louis, MO) and naltrexone hydrochloride (Endo Laboratories, Inc., Garden City, NY) were dissolved in sterile $0.9 \%$ saline; $\beta$-FNA hydrochloride (Dr. D. Zimmerman, Lilly Laboratories, Indianapolis, IN) was dissolved in sterile water. Injections were made into the breast muscle in a volume of $1.0 \mathrm{ml} / \mathrm{kg}$. Doses are expressed in terms of the salts.

\section{Results}

Morphine and naltrexone occasioned responding on the injection-appropriate keys in a dose-related manner and, at large doses, suppressed food-maintained responding (Fig. 1). Pigeons generalized (i.e., greater than 90\% drugappropriate responding) to doses of $3.2-32.0 \mathrm{mg} / \mathrm{kg}$ morphine and to doses of $10.0-32.0 \mathrm{mg} / \mathrm{kg}$ naltrexone. Either morphine or naltrexone suppressed responding in all pigeons at a dose of $56.0 \mathrm{mg} / \mathrm{kg}$.

A single injection of 1.0 or $10.0 \mathrm{mg} / \mathrm{kg} \beta$-FNA did not affect response rate and produced saline-appropriate responding (leftmost points, Fig. 2). Combinations of $\beta$-FNA and small doses of morphine, however, produced some naltrexone-appropriate responding (maximum of $44.9 \pm 24.0 \%$ at a dose combination of $10.0 \mathrm{mg} / \mathrm{kg} \beta$-FNA and $3.2 \mathrm{mg} / \mathrm{kg}$ morphine). Pretreatment with 1.0 or $10.0 \mathrm{mg} / \mathrm{kg} \beta$-FNA attenuated the morphine discriminative stimulus but failed to affect generalization to naltrexone (Fig. 2). The morphine discrimination dose-effect curve was shifted $0.5 \log$ unit to the right by a dose of $1.0 \mathrm{mg} / \mathrm{kg} \beta$-FNA and a dose of $10.0 \mathrm{mg} / \mathrm{kg}$ morphine was required for complete generalization. Pretreatment with $10.0 \mathrm{mg} / \mathrm{kg} \beta$-FNA produced an apparently unsurmountable antagonism of the morphine discriminative stimulus, as indicated by a lack of generalization to morphine up to doses that suppressed responding. Conversely, the doses of naltrexone required for complete generalization were not changed by either pretreatment dose of $\beta$-FNA. $\beta$-FNA failed to attenuate the rate-suppressing effects of morphine or naltrexone.

\section{Discussion}

The antagonist action observed with $\beta$-FNA in the present study was consistent with previous reports on the ability of $\beta$-FNA to attenuate the rate-decreasing effects of morphine in pigeons (France and Woods 1985a) and in other species (c.g., Gmerek and Woods 1985). $\beta$-FNA attenuated in a dose-related manner the discriminative stimulus effects of morphine in pigeons, and was 10 times less potent than naltrexone as an antagonist. A dose of $1.0 \mathrm{mg} / \mathrm{kg} \beta$-FNA produced a shift to the right in the morphine discrimination dose-effect curve that was comparable to the shift produced by $0.1 \mathrm{mg} / \mathrm{kg}$ naltrexone (France and Woods 1985b). The relative potency of $\beta$-FNA and naltrexone for antagonizing the discriminative stimulus effects of morphine was similar to their relative potency for antagonizing the rate-suppressing effects of morphine in pigeons: $\beta$-FNA was 7.5 times less potent than naltrexone at attenuating the rate-suppressing effects of morphine (France and Woods 1985a). These data taken together are consistent with the hypothesis that morphine was exerting its discriminative stimulus effects through the mu receptor in this situation (Woods et al. 1985).

$\beta$-FNA failed to attenuate or augment the discriminative stimulus effects of naltrexone. The lack of substitution by $\beta$-FNA for naltrexone was consistent with previous reports showing that, among a variety of opioid antagonists, only naloxone substitutes for naltrexone in untreated pigeons (Valentino et al. 1983; France and Woods 1985b). Consequently, the behavioral action that $\beta$-FNA and other opioid antagonists have in common with naltrexone (i.e., the capacity to antagonize morphine) clearly is not the predominant action by which naltrexone exerts discriminative stimulus effects in non-dependent animals.

While $\beta$-FNA did not substitute for naltrexone, even at doses larger than $10.0 \mathrm{mg} / \mathrm{kg}$ (France and Woods 1985 b), the combination of small doses of morphine and $\beta$-FNA produced a maximum of $44 \%$ naltrexone-appropriate responding. It is possible, therefore, that the concurrent administration of morphine and an opioid antagonist produces a stimulus that more closely resembles naltrexone than is the case when that antagonist is administered alone (France and Woods 1985b).

Under other conditions and in other species, $\beta$-FNA exerts agonistic actions that are thought to be mediated through kappa opioid receptors and can be reversed by the opioid antagonists naloxone (e.g., Takemori et al. 1981) or quadazocine (Gmerek and Woods 1985). In pigeons, however, some purported kappa agonists (e.g., ethylketocyclazocine) substitute for morphine as discriminative stimuli (Herling et al. 1980; France and Woods 1985b). The lack of morphine-like discriminative stimulus effects with $\beta$-FNA could result from the relative selectivity of ethylketocyclazocine and $\beta$-FNA for kappa receptors or the particular complement of opioid receptor types in pigeons and, therefore, might be specific to this species.

Although the discriminative stimulus effects of opioid antagonists in untreated animals are thought not to be related to opioid systems (e.g., Valentino et al. 1983), morphine and naltrexone interact as discriminative stimuli in a manner that would suggest some contribution of opioid systems to the discriminative stimulus effects of naltrexone. It is well established that naltrexone attenuates the discriminative stimulus effects of morphine, but more recently it has been demonstrated that selected doses of morphine augment the discriminative stimulus effects of naltrexone (France and Woods 1985b). Naltrexone might act through a morphine-sensitive mechanism to exert discriminative stimulus effects in non-dependent animals; however, differential antagonism of morphine but not naltrexone by $\beta$ FNA clearly indicates that morphine and naltrexone do not act via the same receptor system. Sadee and coworkers (Grevel and Sadee 1983; Rosenbaum and Sadee 1982; Rosenbaum et al. 1984) have described an opioid binding site that can be differentiated in vivo from other established binding sites (i.e., mu, kappa, or delta). Naltrexone, naloxone, and morphine bind to this site (lambda) at pharmacologically relevant doses, whereas diprenorphine and many 
other opioid ligands display little or no affinity for this site. While the physiological significance of the lambda binding site has not been established, the pharmacological selectivity of this receptor for only a few opioid ligands correlates well with the direct effects of opioid antagonists in vivo and suggests one possible mechanism by which naltrexone might exert discriminative stimulus effects in untreated animals.

This experiment extends to drug discrimination experiments the conditions under which $\beta$-FNA is an effective antagonist of morphine. Although $\beta$-FNA has an unusually long duration of action (e.g., Gmerek and Woods 1985), its profile of antagonist action does not differentiate it from other antagonists (e.g., diprenorphine) that also attenuate morphine but do not substitute for naltrexone as discriminative stimuli.

Acknowledgements. This research was supported by U.S. Public Health Service Grant DA 00154. The authors thank Scott Nyboer for his excellent technical assistance.

\section{References}

Bertalmio AJ, Herling S, Hampton RY, Winger G, Woods JH (1982) A procedure for the rapid evaluation of the discriminative stimulus effects of drugs. J Pharmacol Methods 7:289-299

France CP, Woods JH (1985a) Antagonistic and rate-suppressing effects of opioid antagonists in the pigeon. $\mathbf{J}$ Pharmacol Exp Ther $235: 442-447$

France CP, Woods JH (1985b) Opiate agonist-antagonist interactions: application of a three-key drug discrimination procedure. J Pharmacol Exp Ther 234:81-89

Gmerek DE, Woods JH (1985) Effects of $\beta$-funaltrexamine in normal and morphine-dependent rhesus monkeys: observational studies. J Pharmacol Exp Ther 235:296-301

Grevel J, Sadee W (1983) An opiate binding site in the rat brain is highly selective for 4,5-epoxymorphinans. Science $221: 1198-1201$
Herling S, Coale EH Jr, Valentino RJ, Hein DW, Woods JH (1980) Narcotic discrimination in pigeons. J Pharmacol Exp Ther 214:139-146

Portoghese PS, Larson DL, Sayre LM, Fries DS, Takemori AE (1980) A novel opioid receptor site directed alkylating agent with irreversible narcotic antagonistic and reversible agonistic activities. J Med Chem 23:233-235

Rosenbaum JS, Sadee W (1982) Demonstration of opiate receptor sub-type in vivo. Life Sci 31:1299-1301

Rosenbaum JS, Holfold NHG, Richards ML, Aman RA, Sadee W (1984) Discrimination of three types of opioid binding sites in rat brain in vivo. Mol Pharmacol 25:242-248

Takemori AE, Larson DL, Portoghese PS (1981) The irreversible narcotic antagonistic and reversible agonistic properties of the fumaramate methyl ester derivative of naltrexone. Eur $J$ Pharmacol 70:445-451

Valentino RJ, Herling S, Woods JH (1983) Discriminative stimulus effects of naltrexone in narcotic-naive and morphine-treated pigeons. J Pharmacol Exp Ther 224:307-313

Ward SJ, Portoghese PS, Takemori AE (1982) Pharmacological characterization in vivo of the novel opioid, $\beta$-funaltrexamine. J Pharmacol Exp Ther 220:494-498

White JM, Holtzman SG (1981) Three-choice drug discrimination in the rat: Morphine, cyclazocine and saline. J Pharmacol Exp Ther 217:254-262

White JM, Holtzman SG (1983) Further characterization of the three-choice morphine, cyclazocine and saline discrimination paradigm: Opioids with agonist and antagonist properties. $\mathbf{J}$ Pharmacol Exp Ther 224:95-99

Woods JH, France CP, Bertalmio AJ, Gmerek DE, Winger G (1985) Behavioral assessment of insurmountable narcotic agonists and antagonists. In: Seiden LS, Balster RL (eds) Behavioral pharmacology: the current status. Alan R. Liss, New York, pp 75-92

Received May 5, 1986 / Final version August 18, 1986 